\title{
Dynamic Filtering of Recognition Memory Codes in the Hippocampus
}

\author{
Sherman P. Wiebe and Ursula V. Stäubli \\ Center for Neural Science, New York University, New York, New York 10003
}

Principal cells of the dentate gyrus (DG), CA3, and CA1 subfields of the hippocampus were recorded in rat during performance of an odor-guided delayed nonmatch-to-sample task with distinct sample and test phases. The hippocampus was found to possess multiple encoding modes. In the sample phase, odor-selective activity was restricted primarily to CA1 and, to a lesser extent, CA3. Odor representations in half of these cells were predictive of subsequent performance (i.e., correct vs error) in the test phase. Cells in each hippocampal subfield maintained elevated or suppressed activity in the delay interval relative to pre-odor baseline, but were indiscriminate with regard to sample odor identity. In the test phase, the regional distribution of odor-selective activity was inverse to that for the sample: maximal in DG and minimal in CA1. The inverted distribution of odor selectivity was also observed for cells that discriminated match/nonmatch trial types. Most match/nonmatch cells exhibited greater activity on correct nonmatch than error match trials, indicating the presence of a hippocampal recognition memory signal on trials where recognition occurred and its absence on trials where recognition failed. These findings reveal the hippocampus as a highly dynamic encoding device, restricting perceptual stimulus information to different subfields (or none, in the delay phase) depending on memory task contingencies. Moreover, the reduction in cue-specificity of match/nonmatch comparison signals as they pass through the hippocampal trisynaptic circuit may contribute to a generalized recognition signal for use in guiding behavior.

Key words: delayed nonmatch-to-sample; dentate gyrus; CA3; CA1; odors; pyramidal cells; granule cells; spatial; match/ nonmatch discrimination; intrahippocampal processing; dynamic filtering; recognition memory; generalization
The delayed nonmatch-to-sample (DNMS) paradigm, commonly used to investigate recognition memory in animals, consists of three phases: sample item presentation followed by a delay interval, and then a recognition phase in which reward follows selection of the nonmatch from among one or more test items. Accurate performance requires the animal to first correctly encode the sample and then discriminate the test stimuli and perform a match/nonmatch $(\mathrm{M} / \mathrm{N})$ comparison with the sample held in memory. Although there remains some debate as to the relative contribution of the hippocampus proper versus adjacent cortical structures to DNMS performance (Jarrard, 1993), there is evidence from lesion studies of both a hippocampal (Wood et al., 1993; Alvarez et al., 1995; Hampson et al., 1999) and parahippocampal cortical (Otto and Eichenbaum, 1992a; Meunier et al., 1993; Mumby and Pinel, 1994) role.

Sample cue-specific neuronal activity has been found in associational cortical areas (e.g., piriform and orbitofrontal cortices) and the parahippocampal (perirhinal and entorhinal) cortical region (Schoenbaum and Eichenbaum, 1995; Young et al., 1997). In the hippocampus, some studies have reported cue-selective responses (Wood et al., 1999), whereas others have not (Otto and Eichenbaum, 1992b). This ambiguity may be attributable to the use of a continuous DNMS protocol in which stimuli are presented sequentially, with reward resulting from recognition of an

\footnotetext{
Received June 25, 1999; revised Aug. 19, 1999; accepted Sept. 22, 1999.

We thank Wendy Suzuki and J. Christopher Repa for critical comments during preparation of this manuscript.

Correspondence should be addressed to Dr. Sherman P. Wiebe, Plexon, Inc., 6500 Greenville Avenue, Suite 730, Dallas, TX 75206. E-mail: sherman@plexoninc.com. Copyright (C) 1999 Society for Neuroscience 0270-6474/99/1910562-13\$05.00/0
}

item as different from its antecedent. In such a paradigm, stimuli are at once both samples for the following item and test cues for the preceding item, thereby potentially obscuring detection of any phase-sensitive coding. Differential activation patterns in response to sample- versus test-phase stimuli have been observed in the hippocampal formation of both animals (Riches et al., 1991; Deadwyler et al., 1996) and humans (Lepage et al., 1998). One objective of this study, therefore, was to compare hippocampal response properties to stimuli presented in distinct sample and test DNMS phases.

Cells with differential responses to matching versus nonmatching test stimuli have been found both in the parahippocampal cortical region and the hippocampus (Miller et al., 1991; Rolls et al., 1993). The cortical match/nonmatch cells are typically stimulus-specific, responding to certain stimuli and not others (Miller and Desimone, 1994; Young et al., 1997), whereas match/ nonmatch signals in the hippocampus, and CA1 in particular, are largely insensitive to stimulus identities (Otto and Eichenbaum, 1992b). The conclusion drawn from these findings is that a functional delineation exists between the hippocampus, mediating abstracted, stimulus-general comparison processing and the adjacent cortical structures with "low level", stimulus-specific comparitor functions (Eichenbaum et al., 1996). The means by which cortical signals are transformed into the generalized recognition code in CA1, however, remains unresolved.

To investigate the role intrahippocampal processing plays in this transformation and to compare hippocampal function during memory encoding and retrieval, DG, CA3, and CA1 principal cells were recorded in rats performing an olfactory DNMS task with distinct sample and test phases. Discriminant analysis and post hoc ANOVAs were used to characterize the functional 
correlates of cells with event-locked firing in relation to odor, position, and match/nonmatch encoding.

\section{MATERIALS AND METHODS}

\section{Subjects}

Adult male Long-Evans rats ( $n=18$; weight at time of surgery, 250-460 $\mathrm{gm})$ were housed individually and given ad libitum food. Water was restricted to that earned during performance of the DNMS task, and to 1-2 $\mathrm{hr}$ per day at the end of each recording session. All animals were trained to stable DNMS performance before and after electrode implantation.

\section{Apparatus}

The odor-cued DNMS task was conducted within a sound-attenuating Y-shaped chamber [sample arm, $36 \times 23 \times 59$ (length $\times$ width $\times$ height) $\mathrm{cm}$; test arms, $27 \times 14 \times 59 \mathrm{~cm}$; central area, $33 \times 23 \times 59 \mathrm{~cm}$ ] enclosed by an electrically grounded copper mesh grid (Fig. 1A). Nosepoke devices consisting of infrared photodetector and light-emitting diode pairs spanning a cylindrical port at the end of each arm were used to control successive DNMS phase transitions (e.g., sample phase $\rightarrow$ delay phase $\rightarrow$ test phase) and to record behavioral events. Additional LEDdetector pairs were used to register arm entry and exit. A $24 \mathrm{~V}$ cue light located above the sample nose port was illuminated during the sample and delay phases. A $24 \mathrm{~V}$ house light mounted on the top of the chamber was illuminated during the test phase. Nosepoke responses were monitored, lights were controlled, and odors were presented as required by a dedicated computer with custom-designed digital I/O interfaces. Odorized airstream concentration and flow rate were set by a flow-dilution olfactometer. Purified air (compressed air filter, Balston) was passed through a flow meter at a rate of $0.51 / \mathrm{min}$ into two $125 \mathrm{ml}$ Erlenmeyer flasks, each containing a small amount $(\sim 5 \mathrm{ml})$ of odor concentrate (Apple Oliffac and Carenko; International Flavors and Fragrances, Inc.). The odor-saturated air leaving the flask was then joined with a purified air stream regulated by a second flow meter at $5 \mathrm{l} / \mathrm{min}$. The odorized air was supplied to the ends of the Y-maze via Tygon tubing and delivered by solenoid valves mounted outside the chamber. Lingering odors were extracted from the apparatus by a ceiling fan and vacuum pump. Water rewards $(0.05 \mathrm{ml})$ were delivered using a gravity-feed system through a solenoid valve to troughs located directly below the test-arm nosepoke devices as required. A high-intensity flashbulb mounted on the ceiling of the chamber was used to signal error responses.

\section{Behavior}

Illumination of a cue light above the sample port marked the start of the DNMS trial. The first sample nosepoke commenced a minimum $2 \mathrm{sec}$ pre-odor period, after which a sample poke turned on the odor (either odor A or odor B). After a minimum of $10 \mathrm{sec}$ of odor exposure, a sample poke terminated the odor and initiated a variable 1-50 sec delay period. The first poke in the sample arm after the delay interval extinguished the cue light, illuminated the ceiling house light, and prompted the delivery of the two odors in the test arms, one odor per arm. The rat exited the sample arm and then discriminated the odors around the entry point of the test arms. Occasionally the rat entered one arm and then, realizing it contained the match odor, backed out and entered the other arm, indicating that the match/nonmatch decision-making process extended right up to the final nosepoke at the end of the arms. The test odors (one in each arm) emanated continually from both arms and could be detected within and just outside the entry point of the arms, regardless of whether a nosepoke was made in the arm. A nosepoke in the nonmatch arm resulted in a $0.05 \mathrm{ml}$ water reward. A match nosepoke triggered a high-intensity flash discharge. Three seconds after both correct and error responses, odor delivery to the test ports was terminated, the house light was extinguished, and an intertrial interval of $20 \mathrm{sec}$ was imposed. The identity of the sample odor and location of the match and nonmatch odors were randomized across trials. Figure $1 B$ diagrams the behavioral events in the two-odor DNMS task, and Figure $1 C$ shows the mean performance curve per session summed over all rats, with 100-250 trials per session. Delay-dependent performance ranged from $86 \%$ correct at $0-5 \mathrm{sec}$ delays to $74 \%$ correct at $45-50 \mathrm{sec}$ delays.

\section{Training procedure}

Training on the two-odor DNMS task was accomplished in a series of four stages. In the first stage, the rat was trained to execute sequential nosepokes in the sample and test arms by placing $0.05 \mathrm{ml}$ water incen- tives. After 15-20 sample and test pokes were completed, test-arm water rewards were made contingent on a preceding sample arm poke, which was no longer rewarded (stage two). Both stage one and two of training were conducted with the ceiling house light illuminated throughout. After successful completion of 50 sample poke $\rightarrow$ test poke sequences in stage two, the olfactory component of the task was introduced in stage three as follows.

At the beginning of the trial, the cue light above the sample port was illuminated, and the ceiling house light was extinguished. The first sample nosepoke resulted in commencement of a pre-odor period lasting at least $2 \mathrm{sec}$. The following sample nosepoke initiated the presentation of the sample odor for a minimum of $10 \mathrm{sec}$. After $10 \mathrm{sec}$, the next sample nosepoke terminated both the odor and the cue light, illuminated the ceiling house light, and turned on the two odors in the test arms. A nosepoke at the end of the nonmatch arm resulted in a $0.05 \mathrm{ml}$ water reward. A nosepoke in the match arm caused the high-intensity flashbulb mounted on the ceiling to discharge. Three seconds after both correct and error responses, odors in the test arms were terminated, the house light was extinguished, and an intertrial interval of $20 \mathrm{sec}$ was imposed. After the intertrial interval had expired, the cue light above the sample port was once again illuminated, signaling the start of the next trial.

The location of the match and nonmatch arms were randomized across trials in stage three of the training protocol. The same sample odor was repeatedly given trial after trial until a performance of $\geq 90 \%$ correct had been accomplished over 20 consecutive trials. Once this occurred, the sample odor was switched, and the other odor was used until a percentage of correct responding of $\geq 90 \%$ over 20 consecutive trials had been performed. The sample odor was switched back and forth in this manner until the number of trials required to reach $\geq 90 \%$ over 20 consecutive trials gradually approached 20 , at which point the criterion performance level was changed to $\geq 90 \%$ correct over 10 consecutive trials. After a series of five to eight such sample odor switches with the 10-trial criteria, the sample odor identity was made random from trial to trial. Ninety percent correct responding on the task with the sample odor randomized across trials marked the end of the third training phase.

In the fourth and final stage of training, a variable delay was introduced between the sample and test phases. After the minimum $10 \mathrm{sec}$ exposure period to the sample odor, a nosepoke turned off the odor and initiated the random delay period, first ranging from 0 to $10 \mathrm{sec}$ and then extending up to a range of $0-50 \mathrm{sec}$. During the delay period, the sample cue light remained illuminated. After the delay interval had expired, the following sample nosepoke initiated the test phase as described above in stage three, with the location of the match and nonmatch arms randomized across trials. Odor delivery in the test arms continued up to three seconds after the test poke response, after which the odors were terminated, the house light was extinguished, and an intertrial interval of 20 sec was imposed.

The average time required to train naive animals to criterion $(85 \%$ correct on $0-5 \mathrm{sec}$ delay trials) in the task with $1-50 \mathrm{sec}$ delays was $\sim 1$ month. Typical training sessions consisted of 100-250 DNMS trials over 5-8 hr. All animals $(n=18)$ were trained and performed at criterion levels during sessions in which electrophysiological data were collected.

\section{Surgical procedure}

When animals reached criterion performance on the DNMS task, they were surgically implanted with a microwire electrode array (NBLabs, Denison, TX; www.nblabslarry.com) consisting of two rows (row separation, $0.8 \mathrm{~mm}$ ) of eight $50 \mu \mathrm{m}$ Teflon-coated, stainless steel microwires (pair separation, $200 \mu \mathrm{m}$ ). A diagram of the microwire electrode recording array is shown in Figure $2 A$. To help eliminate low-frequency movement artifacts caused by active behaving animals, recording signals were subtracted from that of a reference wire located just posterior and at the same depth as the array. The reference wire had a deinsulated tip $(200 \mu \mathrm{m})$ which, with its low impedance, served as a low-pass filter. The rat was anesthetized with a single intraperitoneal injection of sodium pentobarbital $(50 \mathrm{mg} / \mathrm{kg})$. Atropine was administered $(0.1 \mathrm{mg} / \mathrm{kg}$, i.p.) to reduce mucous secretions. Supplementary intraperitoneal pentobarbital injections $(8 \mathrm{mg} / \mathrm{kg})$ were given when necessary to assure deep anesthesia. Body temperature was maintained throughout surgery at $37^{\circ} \mathrm{C}$ with a thermal heating pad. After transfer to the stereotaxic apparatus (David Kopf), a midsagittal skin incision was made, soft tissue was retracted, and the periosteum of the skull was removed. Six stainless steel screws (Frederick Haer and Co.) were firmly attached to the skull, both to ensure proper anchoring of the probe array and for grounding purposes. A small oval craniotomy was then performed on the right parietal bone 


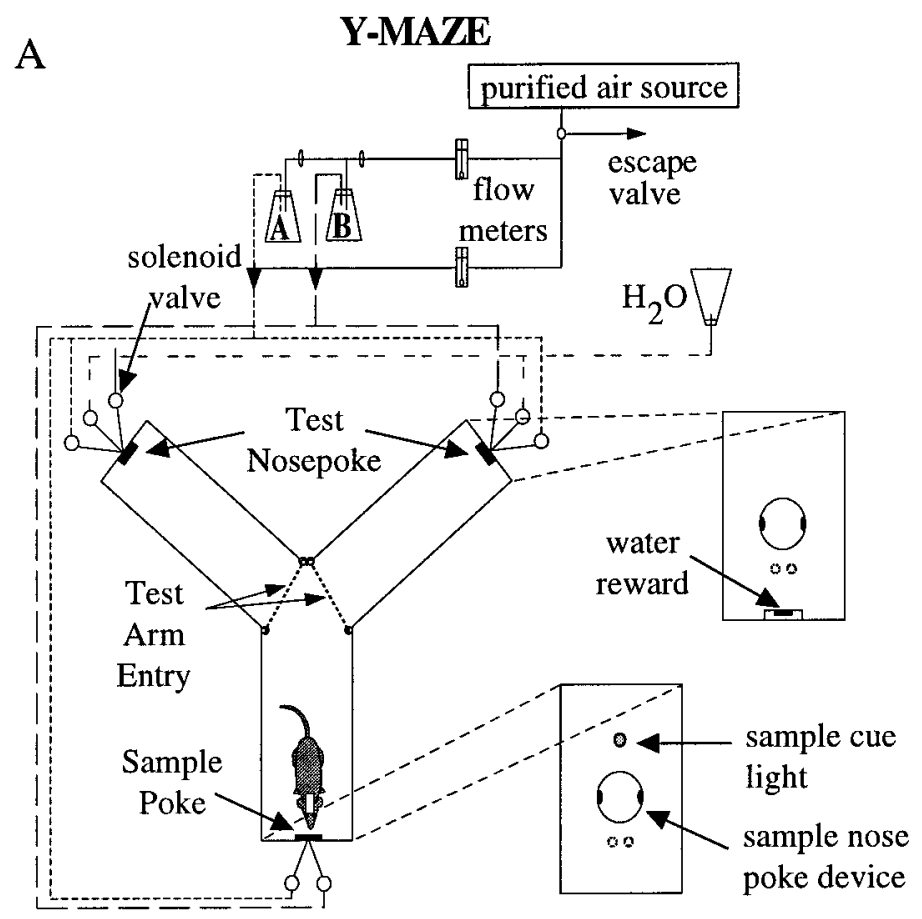

B

DNMS PARADIGM

Figure 1. A, Y-shaped apparatus for DNMS task. A nosepoke in the sample arm was required to initiate the trial with a minimum $2 \mathrm{sec}$ pre-odor period, after which a sample poke turned on the odor (either odor A or B). After $10 \mathrm{sec}$ of odor exposure, a sample poke turned off the odor and initiated a variable $0-60 \mathrm{sec}$ delay. The first poke after the delay interval turned off a cue light above the sample port, turned on a house light, and prompted the start of the test phase with the delivery of the two odors in the test arms (one per arm). Infrared beams detected the rat's exit from the sample arm, entry into the left and right test arms, and subsequent nosepoke response. A nosepoke in the nonmatch arm resulted in water reinforcement. A match nosepoke response triggered the discharge of a light flash. Three seconds after the reinforcement signal, the odors were terminated, the house light was extinguished, and an intertrial interval of $20 \mathrm{sec}$ was imposed. After the intertrial interval, the cue light above the sample port was again turned on, prompting the rat to execute a sample nosepoke to initiate another trial. The identity of the sample odor and the location of the match and nonmatch test odors were randomized across trials. $B$, Schematic of DNMS Paradigm. $C$, Delaydependent performance in the DNMS task. Mean \pm SEM percentage of correct trials per recording session (100-250 trials) was averaged over 435 sessions in 18 rats. Trials were grouped in $5 \mathrm{sec}$ intervals and plotted across the $1-50 \mathrm{sec}$ delay period. Note: On $x$-axis, 5 implies $0-5 \mathrm{sec}, 10$ implies $5-10 \mathrm{sec}$, etc.

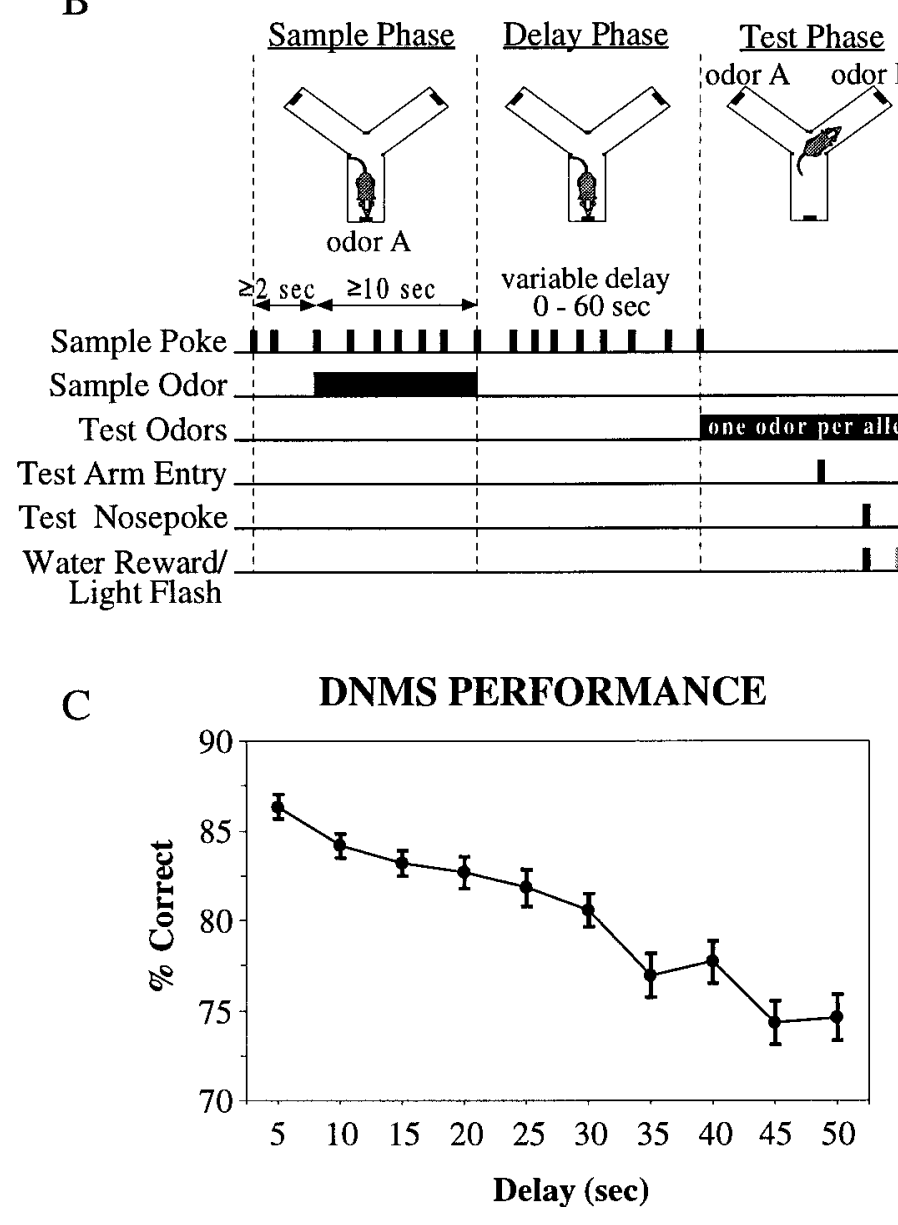




\section{A. Electrode Array}

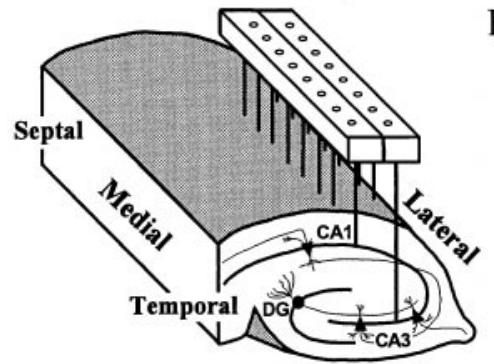

C. Waveform Discrimination

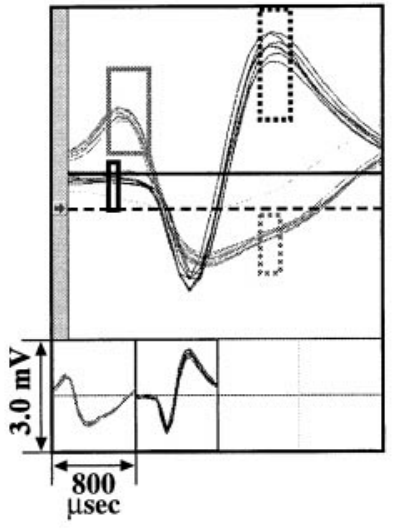

B. Electrode placement

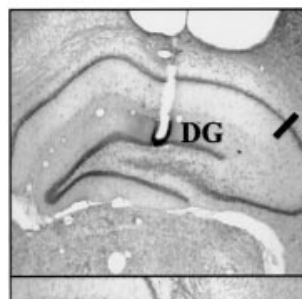

D. Plot of firing rate vs. spike width

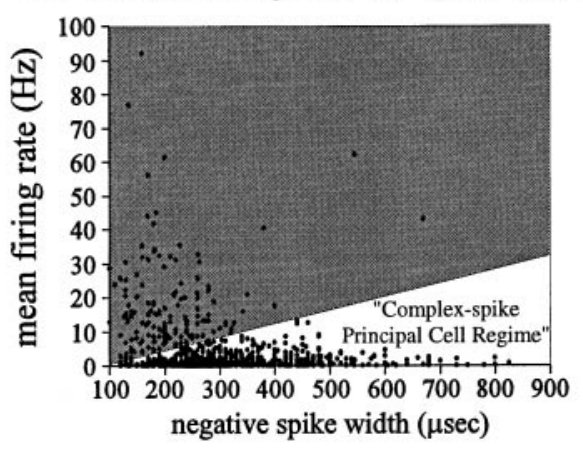

Figure 2. A, Diagram of microwire electrode recording array. The array consisted of two parallel rows of $50 \mu \mathrm{m}$ stainless steel microwires (row separation, $800 \mu \mathrm{m}$; pair separation, $200 \mu \mathrm{m}$ ) oriented along the septotemporal axis of the hippocampus, positioned to record from the pyramidal cells in the CA3 and CA1 fields and the granule cells in the dentate gyrus. $B$, Histological verification of microwire placement in the principal cell layers. Examples of electrode placement in the dentate granule cell layer (top) and the CA3 (middle) and CA1 (bottom) pyramidal cell layers. The black line in each image marks the CA3/CA1 boundary. $C$, Timeamplitude window discrimination of extracellularly recorded action potentials. Up to four neurons could be discriminated per microwire channel. In the example shown, two distinct units with well defined waveform characteristics were discriminated. $D$, Physiological identification of principal cells by extracellular recording parameters. The mean firing rate of each cell during task performance was plotted against the duration of the negative phase of the extracellular waveform. Cells with low mean firing rates and large negative spike widths were categorized as principal cells. A linear cutoff was used in firing rate-spike width space to separate principal cells $[1.1 \pm 0.05 \mathrm{~Hz} ; 305 \pm 3 \mu \mathrm{sec}$ (mean $\pm \mathrm{SEM}$ ); $n=1101]$ from interneurons $(17.4 \pm 1.13 \mathrm{~Hz} ; 206 \pm 6 \mu \mathrm{sec} ; n=139)$.

and the electrode assembly implanted vertically with a microdrive. The center pair of array electrodes was positioned at coordinates $4.0 \mathrm{~mm}$ posterior to bregma and $3.3 \mathrm{~mm}(2.8 \mathrm{~mm})$ lateral to midline for CA3 (DG and CA1) placement. The longitudinal axis of the array was rotated to a $30^{\circ}$ angle from midline, with the anterior end more medial and the posterior end more lateral, to follow the contour of the hippocampus. The array was driven slowly $(\sim 25 \mu \mathrm{m} / \mathrm{min})$ through the brain to a depth ranging from $3.4-4.0 \mathrm{~mm}$ for CA3 to $2.2-3.2 \mathrm{~mm}$ for CA1. Neural activity from the microwire electrodes was monitored throughout surgery to ensure placement near the hippocampal cell layers. After array placement, the cranium was sealed with bone wax and dental cement, and the animal was allowed to recover for $6-7 \mathrm{~d}$ before DNMS retraining and recording commenced. The scalp wound was treated periodically with Neosporin antibiotic to prevent infection.

At the conclusion of recording, each subject was administered a lethal dose of sodium pentobarbital $(100 \mathrm{mg} / \mathrm{kg})$, and $40 \mu \mathrm{A}$ current was passed for $1 \mathrm{sec}$ through each of the 16 recording electrodes. The animal was then perfused transcardially with $0.9 \%$ saline $/ 0.1 \%$ heparan followed by $10 \%$ buffered formalin. The brain was removed from the skull and stored in a $10 \%$ buffered formalin $/ 30 \%$ sucrose $/ 2 \%$ potassium ferrocyanide solution. This produced a Prussian blue reaction that aided the localization of the electrode tips (Fig. $2 B$ ). After the brain absorbed the solution $(\sim 36 \mathrm{hr})$, it was placed in $10 \%$ buffered formalin for an additional $24-48$ hr. Coronal sections of $40 \mu \mathrm{m}$ thickness were cut on a freezing microtome, mounted, and stained with cresyl violet to aid in visualization of the cell body layers. All animal care and experimental procedures conformed to National Institutes of Health and Society for Neuroscience guidelines for care and use of experimental animals.

\section{Multineuron recording technique}

A head stage (NB Labs, Dennison, TX) containing 17 standard field effect transistors (16 for the recording wires and one for the deinsulated reference wire) was used to connect to an 18 channel plastic connector (18th lead connected to the skull screw and used as ground), cemented to the animals head. High-fidelity insulated cables connected the headstage with a preamplifier (gain 50, bandpass $100 \mathrm{~Hz}$ to $8 \mathrm{kHz}$ ) via a 45 channel commutator (Josef Biela; Idea Development) centrally located on top of the chamber. The preamplifier output was connected through a ribbon cable to a Multichannel Neuronal Acquisition Processor (MNAP) system (Plexon, Dallas, TX; www.plexoninc.com) that performed on-line multichannel neuronal spike sorting. Signals passed through input boards, which provided programmable gain and additional band-pass filtering (set at $400 \mathrm{~Hz}$ to $5 \mathrm{kHz}$ ), and then to digital signal processing channels for spike discrimination. Neural activity (extracellular action potentials, or "spikes") and behavioral responses (infrared beam interruptions and nosepokes) were digitized and time-stamped for computer processing in relation to successive behavioral events within each DNMS trial. Neuronal action potentials were digitized at $40 \mathrm{kHz}$ and isolated by timeamplitude window discrimination and template matching (Fig. $2 C$ ). Up to four single units could be isolated per microwire channel. Control software for the MNAP box ran on a host Pentium PC, allowing digital control of signal gain, filtering, and window discrimination parameters. Identified spikes were tracked from session to session by waveform and firing characteristics within the task (perievent histograms). To maximize the likelihood that single units were recorded, only waveforms with zero spike counts in the first $1 \mathrm{msec}$ time bin of their interspike interval histogram were included in the analysis. Also, to help ensure that the same neurons were recorded continuously over time, waveforms were required to have stable perievent firing rates across recording sessions. Although it is possible that the neuronal spikes discriminated on a given microwire may not have isolated single units or consistently identified the same unit over time (McNaughton et al., 1983), selecting only waveforms with absolute $1 \mathrm{msec}$ refractory periods and constant firing rates and behavioral correlates across recording sessions greatly reduced the likelihood that different or multiple neurons were mistaken as single units (Deadwyler et al., 1996).

Principal cells in the dentate gyrus and CA fields can be distinguished from interneurons based on their physiological characteristics. Granule cells (Mizumori et al., 1989; Jung and McNaughton, 1993) and pyramidal cells (Ranck, 1973) fire at low $(\leq 2 \mathrm{~Hz})$ overall mean firing rates and possess large spike widths (most with $\geq 250 \mu \mathrm{sec}$ negative-going spike widths) in contrast to interneurons in DG and CA fields, which exhibit high $(>5 \mathrm{~Hz})$ mean firing rates and narrow $(<250 \mu \mathrm{sec}$, negative-going) spike widths. Therefore, only units with low overall mean firing rates $(1.1 \pm 0.05 \mathrm{~Hz}$; mean $\pm \mathrm{SEM} ; n=1101)$ and large negative-going spike widths $(305 \pm 3 \mu \mathrm{sec})$ characteristic of DG granule cells and CA3/1 pyramidal cells were used in this study (Fig. $2 D$ ). 
Table 1. Perievent histogram parameters

Discriminant analysis groups

\begin{tabular}{|c|c|c|c|c|c|c|c|}
\hline \multirow[b]{2}{*}{$\begin{array}{l}\text { Perievent histogram } \\
\text { name }\end{array}$} & \multirow[b]{2}{*}{ Event } & \multirow[b]{2}{*}{$\begin{array}{l}\text { Bin width } \\
(\mathrm{sec})\end{array}$} & \multirow[b]{2}{*}{$\begin{array}{l}\text { Histogram limits } \\
(\mathrm{sec})\end{array}$} & & & & \\
\hline & & & & $\mathrm{L} / \mathrm{R}$ & $\begin{array}{l}\text { Sample odor } \\
\text { A/B }\end{array}$ & $\begin{array}{l}\text { Test odor } \\
\text { A/B }\end{array}$ & $\mathrm{M} / \mathrm{N}$ or $\mathrm{C} / \mathrm{E}$ \\
\hline Pre-Odor & Sample odor on & 0.25 and 1.0 & {$[-5.0,-1.0]$} & - & - & - & - \\
\hline Odor fast & Sample odor on & 0.25 & {$[-0.5,1.5]$} & - & $\sqrt{ }$ & - & $\sqrt{ }$ \\
\hline Odor slow & Sample odor on & 1.00 & {$[1.5,9.5]$} & - & $\sqrt{ }$ & - & $\sqrt{ }$ \\
\hline Odor off & Sample odor off & 0.25 & {$[-0.5,1.0]$} & - & $\checkmark$ & - & $\checkmark$ \\
\hline Delay & Odor off (delay $\geq 5 \mathrm{sec}$ ) & 1.00 & {$[1.0,5.0]$} & - & $\checkmark$ & - & $\checkmark$ \\
\hline Test entry & Test arm entry & 0.25 & {$[-0.5,0.5]$} & $\checkmark$ & - & $\sqrt{ }$ & $\checkmark$ \\
\hline Prepoke & Test nosepoke & 0.25 & {$[-1.0,0.0]$} & $\sqrt{ }$ & - & $\sqrt{ }$ & $\checkmark$ \\
\hline Postpoke & Test nosepoke & 0.25 & {$[0.0,3.0]$} & $\sqrt{ }$ & - & $\sqrt{ }$ & $\checkmark$ \\
\hline
\end{tabular}

Sample phase: odor fast, odor slow, odor off. Delay phase: delay. Test phase: test entry, prepoke, postpoke.

\section{Analysis}

Event encoding. Perievent histograms were generated for each cell around each DNMS event. The associated event, bin width, histogram boundary limits, and grouping factors for each perievent histogram are shown in Table 1. Event encoding was determined by comparing the firing rate within each histogram with its appropriate baseline period. For perievent histograms in the test phase, in which the rat's position was different for each event, the baseline used was the mean firing rate of the cell over the entire trial. A neuron was classified as "test cell" if there was a significant (ANOVA; $p<0.01$ ) increase in firing around one of the test-phase events (i.e., in one or more perievent histogram bins; see Table 1 for bin size used for each event) relative to baseline. Only increases in firing rates were considered for nonstationary test-phase events to avoid counting events within nonfiring regions of place cells as "encoded." For sample and delay phases, in which the rat's location was fixed, the pre-odor interval at the sample port was used as the baseline reference period. A cell was classified as a "sample cell" or "delay cell" if there was a significant change (either enhancement or suppression) in the firing rate in one or more perievent bins relative to pre-odor baseline. Further discriminant analyses were then performed on each event-responsive cell.

Discriminant analysis. The test-phase perievent histograms constructed around the test arm entry and poke response consisted of three groups or factors: position (L/R), odor (A/B), and trial type (match/nonmatch). The sample- and delay-phase perievent histograms constructed around odor onset and offset consisted of two factors: odor (A/B) and trial type (correct/error). (Note: correct/error in the sample and delay phases refer to trials in which a nonmatch or match response, respectively, was later made in the test phase).

Linear discriminant analysis (Rencher, 1995) was performed on perievent histograms of event-encoding cells in the following manner. For cell $c$ and perievent histogram $h$, the between-group covariance matrix $B_{\mathrm{c}, \mathrm{h}}$ and the within-group covariance matrix $W_{\mathrm{c}, \mathrm{h}}$ were derived from the firing rate vector $X_{\mathrm{c}, \mathrm{h}}=X_{\mathrm{c}, \mathrm{h}}\left[1,2, \ldots\right.$, Nbins $\left._{\mathrm{h}}\right]$, where $N$ bins $_{\mathrm{h}}=$ number of time bins in perievent histogram $h$. The eigenvectors $E_{\mathrm{c}, \mathrm{h}}=$ $E_{\mathrm{c}, \mathrm{h}}\left[1,2, \ldots, n_{\mathrm{e}}\right]$ and corresponding eigenvalues $\lambda_{\mathrm{c}, \mathrm{h}}$ of the matrix $\left(B_{\mathrm{c}, \mathrm{h}} \cdot\right.$ $W_{\mathrm{c}, \mathrm{h}}{ }^{-1}$ ) were then calculated. The number of eigenvectors and eigenvalues extracted was Nfunctions $=\min \left\{\right.$ Ngroups $_{\mathrm{h}}-1$, Nbins $\left._{\mathrm{h}}\right\}$, where Ngroups $_{\mathrm{h}}$ was the number of group categories for histogram $h$. The ability of the $i^{\text {th }}$ eigenvector $\left(E_{\mathrm{c}, \mathrm{h}}^{\mathrm{i}}\right)$ to separate one or more of the $\operatorname{Ngroups}_{\mathrm{h}}$ groups by serving as coefficients for discriminant functions $D^{\mathrm{i}}{ }_{\mathrm{c}, \mathrm{h}}=E_{\mathrm{c}, \mathrm{h}}^{\mathrm{i}}{ }^{\text {. }}$ $X_{\mathrm{c}, \mathrm{h}}$ was determined using the $\chi^{2}$ approximation of the Wilks $\Lambda$ statistic, distributed with $\left(\left(\right.\right.$ Nbins $\left._{\mathrm{h}}-i+1\right) *\left(\right.$ Ngroups $\left.\left._{\mathrm{h}}-i\right)\right)$ degrees of freedom. The discriminant functions were normalized such that each $D^{\mathrm{i}}{ }_{\mathrm{c}, \mathrm{h}}$ was normally distributed with mean $=0$ and $\mathrm{SD}=1$ over all groups. Discriminant functions with significance values of $p<0.01$ as determined by the $\chi^{2}$ statistic were then further analyzed using post hoc twoand three-way ANOVAs to determine which groups were separated (ANOVA, significant main effect; $p<0.01$ ). A simplified schematic illustration of discriminant analysis is shown in Figure 3.

\section{RESULTS}

\section{Neuronal activity correlated to DNMS events}

A total of 1101 principal cells were isolated from the dentate gyrus $(n=129)$, field CA3 $(n=767)$, and field CA1 $(n=205)$ of

\section{Discriminant Analysis}
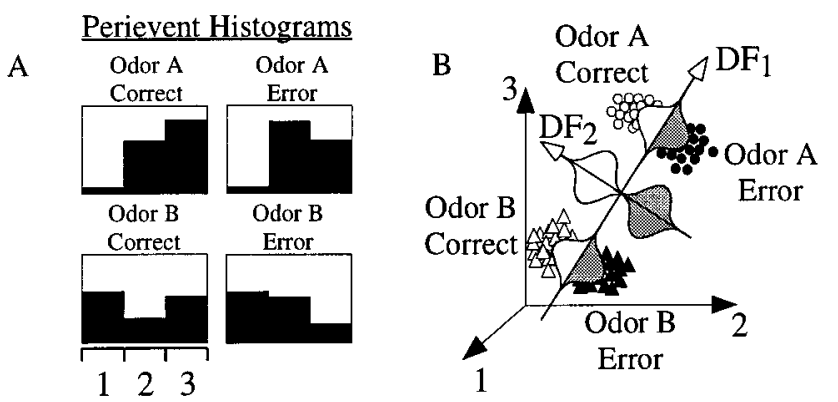

Time Bin

Figure 3. Schematic illustration of linear discriminant analysis. A, Perievent histograms of neural activity were composed for each of the groups (for example, group $1=$ odor $\mathrm{A}$, correct trials; group $2=$ odor $\mathrm{A}$, error trials; group $3=$ odor $\mathrm{B}$, correct trials; group $4=$ odor $\mathrm{B}$, error trials). $B$, The firing rate within each time bin for each trial was plotted in $n$-dimensional space, where $n=$ number of time bins. Directions [discriminant functions (DFs)] were then computed that maximally separated groups as follows. The first discriminant function $\left(\mathrm{DF}_{1}\right)$ was chosen such that the data projection onto it [depicted by Gaussian curves in $(B)$ ] accounted for maximal variance between groups. In this example, the first discriminant function separated odor A from odor B trials, but not correct versus error trials. The second discriminant function $\left(\mathrm{DF}_{2}\right)$ was then selected, which maximized the variance between groups and was uncorrelated (linearly independent) with $\mathrm{DF}_{1}$. In this case, the second discriminant function separated correct from error trials, and not odor A from odor B trials. Subsequent discriminant functions maximized variance of the data uncorrelated with previous DFs. A total of minimum (number of time bins, number of groups - 1) discriminant functions were calculated. The ability of a discriminant function to separate one or more of the groups was determined using a $\chi^{2}$ approximation of the Wilks $\Lambda$ statistic. Significant discriminant functions $(p<0.01)$ were then analyzed using post hoc ANOVAs to determine which groups were separated.

18 rats during criterion performance of the DNMS task. The units were recorded during an average of 24 sessions per rat. All DNMS events were encoded by some subset of principal cells (Fig. 4). Some units responded to just a single event (Fig. 4B,D, $E$ ) whereas others were responsive to more than one (Fig. $4 A, C, F)$. The cell shown in Figure $4 A$ exhibited activity timelocked to sample odor onset (odor fast, $F_{(1,2783)}=622.40 ; p<$ $0.01)$ and offset $\left(F_{(1,2783)}=150.75 ; p<0.01\right)$, whereas Figure $4 B$ shows a cell with suppressed activity around sample-odor onset (odor fast, $\left.F_{(1,3026)}=11.48 ; p<0.01\right)$ and offset $\left(F_{(1,3026)}=9.33\right.$; $p<0.01$ ), and elevated slow sample-odor onset firing (odor slow, $\left.F_{(1,943)}=32.96 ; p<0.01\right)$. Figure $4 C$ depicts a cell with a 


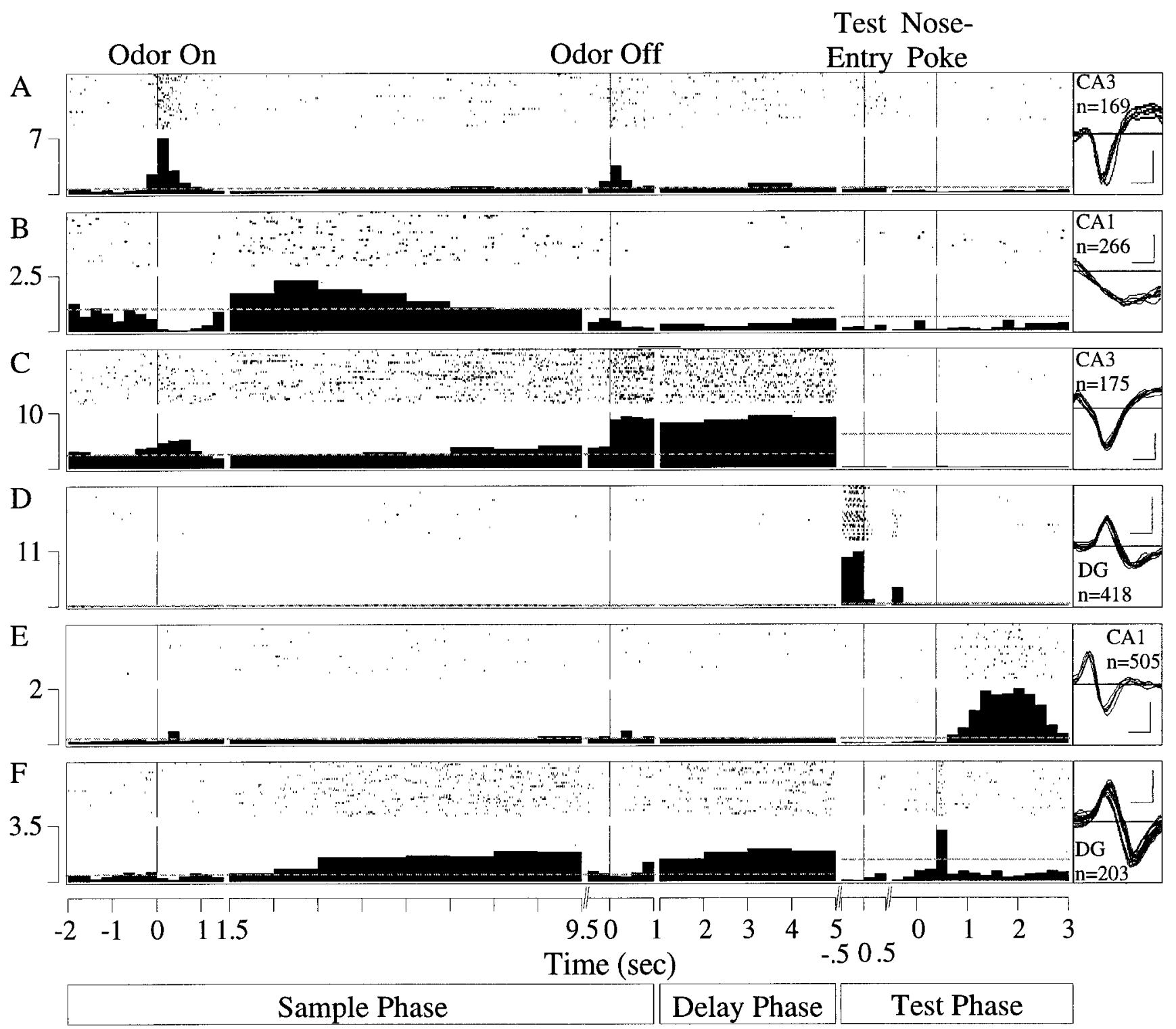

Figure 4. Examples of hippocampal principal cells encoding different DNMS events. Each panel includes a raster display of 30 representative trials and a summary histogram of perievent activity in spikes per second summed across all trials in 250 msec bins, except in the slow sample-odor onset and delay intervals where $1 \mathrm{sec}$ bins were used. The responsivity of cells was determined by comparing the firing rate within each perievent histogram with baseline activity. For perievent histograms in the sample and delay phases in which the rat's location was fixed, the pre-odor interval was used as the baseline reference period (represented as a dotted line extending throughout the sample and delay phase). A cell was classified as encoding an event in the sample or delay phases if there was a significant (ANOVA; $p<0.01$ ) change in firing in one or more perievent histogram bins. For perievent histograms in the test phase in which the rat's position was different for each event, the baseline used was mean firing rate over the entire trial (represented as a dotted line extending throughout the test phase). A cell was classified as encoding an event in the test phase if there was a significant $(p<0.01)$ increase in firing rate in one or more of the perievent histogram bins compared to baseline. The extracellularly recorded waveform (negative deflection-down; calibration: $100 \mu \mathrm{V}, 200 \mu \mathrm{sec}$ ), hippocampal field, and number of DNMS trials recorded for each cell $(n)$ are shown to the right of each panel. $A$, A cell with activity time-locked to sample odor onset and offset. $B$, A cell that exhibited suppressed activity around sample-odor onset and offset and elevated slow sample-odor onset firing. $C$, A cell with a sample-odor onset and offset response as well as delay firing. $D$, A cell that encoded entry into the test arms. $E$, A cell that fired maximally in the postresponse period. $F$, A multiphase cell that exhibited a slow sample odor response, delay activity, and firing time-locked to the test-poke response.

sample-odor onset (odor fast, $F_{(1,1718)}=26.08 ; p<0.01$ ) and offset (odor off, $F_{(1,1718)}=142.54 ; p<0.01$ ) response as well as delay firing $\left(F_{(1,593)}=8.06 ; p<0.01\right)$. Other cells are shown in Figure $4 D$, with increased activity during entry into the test arms $\left(F_{(1,78725)}=9.87 ; p<0.01\right)$, and Figure $4 E$, with maximal firing in the postnosepoke period $\left(F_{(1,94481)}=957.59 ; p<0.01\right)$. A multiphase cell that exhibited a slow sample odor response $\left(F_{(1,744)}=152.34 ; p<0.01\right)$, delay activity $\left(F_{(1,744)}=12.24 ; p<\right.$
0.01 ), and firing time-locked to the test-poke response (postresponse, $\left.F_{(1,54209)}=804.20 ; p<0.01\right)$ is displayed in Figure $4 F$.

Approximately $70 \%$ of the cells in each field (699 of 1101 overall) were responsive to events in the sample phase (sample cells), $\sim 30 \%$ (294 of 1101) in the delay phase (delay cells), and $\sim 55 \%$ (571 of 1101) in the test phase (test cells) (Table 2). Responsive cells were further analyzed to determine whether their activity differentiated odor, match/nonmatch trial type (re- 
Table 2. Number of cells encoding events in the sample, delay, and test phases

\begin{tabular}{|c|c|c|c|c|c|c|c|c|c|c|c|}
\hline & \multicolumn{3}{|c|}{ Sample cells (responsive) } & & \multicolumn{3}{|c|}{ Delay cells } & & \multicolumn{3}{|c|}{ Test cells } \\
\hline & \multirow{2}{*}{$\begin{array}{l}\frac{\mathrm{DG}}{96} \\
(74 \%)\end{array}$} & \multirow{2}{*}{$\begin{array}{l}\frac{\mathrm{CA} 3}{458} \\
(60 \%)\end{array}$} & \multirow{2}{*}{$\begin{array}{l}\frac{\mathrm{CA} 1}{145} \\
(71 \%)\end{array}$} & & \multirow{2}{*}{$\begin{array}{l}\frac{\mathrm{DG}}{37} \\
(29 \%)\end{array}$} & \multirow{2}{*}{$\begin{array}{l}\frac{\mathrm{CA} 3}{184} \\
(24 \%)\end{array}$} & \multirow{2}{*}{$\begin{array}{l}\frac{\mathrm{CA} 1}{73} \\
(36 \%)\end{array}$} & & \multirow{2}{*}{$\begin{array}{l}\frac{\mathrm{DG}}{75} \\
(58 \%)\end{array}$} & \multirow{2}{*}{$\begin{array}{l}\text { CA3 } \\
383 \\
(50 \%)\end{array}$} & \multirow{2}{*}{$\begin{array}{l}\text { CA1 } \\
113 \\
(55 \%)\end{array}$} \\
\hline & & & & & & & & & & & \\
\hline Odor (selective) & 3 & 36 & 14 & Odor & 0 & 0 & 0 & Odor & 1 & 8 & 1 \\
\hline $\mathrm{C} / \mathrm{E}$ & 1 & 19 & 3 & $\mathrm{C} / \mathrm{E}$ & 0 & 0 & 0 & $\mathrm{M} / \mathrm{N}$ & 1 & 2 & 4 \\
\hline \multirow[t]{8}{*}{ Odor \& $\mathrm{C} / \mathrm{E}$} & 4 & 31 & 12 & Odor \& $\mathrm{C} / \mathrm{E}$ & 0 & 0 & 0 & Position & 23 & 135 & 37 \\
\hline & & & & & & & & Odor \& position & 13 & 63 & 17 \\
\hline & & & & & & & & $\mathrm{M} / \mathrm{N} \&$ position & 6 & 42 & 14 \\
\hline & & & & & & & & Odor \& $\mathrm{M} / \mathrm{N}$ & 0 & 1 & 1 \\
\hline & & & & & & & & Odor \& $\mathrm{M} / \mathrm{N} \&$ position & 10 & 31 & 9 \\
\hline & & & & & & & & Exclusive odor* & 1 & 7 & 1 \\
\hline & & & & & & & & Exclusive $\mathrm{M} / \mathrm{N}^{*}$ & 0 & 1 & 4 \\
\hline & & & & & & & & Exclusive position* & 17 & 107 & 25 \\
\hline
\end{tabular}

*Exclusive: no other main effects or interaction effects on post hoc ANOVA.

$n$ (total): $\mathrm{DG}=129 ; \mathrm{CA} 3=767 ; \mathrm{CA} 1=205$.

Responsive cells: significant change in firing relative to baseline; ANOVA; $p<0.01$.

Responsive cells with selective encoding: discriminant analysis, $\chi^{2}, p<0.01$ and main effect on post hoc ANOVA; $p<0.01$.

ferred to as correct/error for the sample and delay phases), or position as determined by discriminant analysis $\left(\chi^{2} ; p<0.01\right)$ and significant main effects on post hoc ANOVAs $(p<0.01)$.

\section{Sample odor selectivity}

Odor-selective activity most prominent in CA1, least in DG, and linked to task performance

If hippocampal representations of the sample odor mediate later recognition in the test phase, then sample odor codes in the hippocampus should be different in trials where correct recognition of the sample occurred later in the test phase compared to error trials where recognition failed. Activity in some cells discriminated the sample odor but did not fire differentially on correct versus error $(\mathrm{C} / \mathrm{E})$ trials (Fig. $5 A, \chi^{2}{ }_{(9)}=53.54, p<0.01$; odor, $F_{(1,107)}=31.89, p<0.01 ; \mathrm{C} / \mathrm{E}, F_{(1,107)}=0.07$, NS). Other cells, however, fired only for one odor, and during either only correct or only error trials (Fig. $5 B, \chi_{(24)}^{2}=54.60, p<0.01$; odor, $\left.F_{(1,235)}=10.54, p<0.01 ; \mathrm{C} / \mathrm{E}, F_{(1,235)}=7.53, p<0.01\right)$.

The number of cells in each field responsive to the sample odor onset (fast and slow responses) and offset is shown in Table 3. Although both dentate and CA3/1 cells discriminated odor on its immediate onset (up to $1.5 \mathrm{sec}$ after its onset) in the odor-fast period $(5 / 56=9 \%$ of the responsive DG cells; $38 / 381=10 \%$ in CA3/1), only cells in the CA fields exhibited longer-latency, odor-specific responses in the subsequent odor-slow period $(>1.5$ sec after odor onset) (odor discrimination, $0 / 70=0 \%$ of DG cells compared to $49 / 433=11 \%$ in CA3/1).

Responsive cells in the sample phase (including the odor-fast, odor-slow, and odor-off intervals) were then tallied for each subfield (Table 2). Summing over the hippocampal subfields, odor-selective activity was observed in $100 / 699=14 \%$ of the sample-responsive cells, half of which (47/100) were correlated with trial performance (differential correct/error firing), whereas $10 \%(70 / 699)$ of the sample-responsive cells discriminated correct/error trials (Fig. 6A). Odor-selective firing was unevenly distributed across the subfields, least prevalent in the dentate gyrus $(7 / 96=7 \%$ of the sample cells $)$, more in CA3 $(67 / 458=$ $14 \%)$, and most prevalent in CA1 $(26 / 145=18 \%)($ Fig. $6 B)$.

\section{Delay activity}

Sample nonspecific delay firing

Whereas $\sim 25 \%(294 / 1101)$ of the hippocampal cells exhibited elevated or suppressed activity in the delay relative to the preodor period, none $(0 / 294)$ differentiated the sample odor or $\mathrm{C} / \mathrm{E}$ trials (Table 2, Fig. 6A). Most delay firing was restricted to the sample arm location and terminated before entry into the test arms (Fig. 4C).

\section{Recognition-phase encoding}

Central to the DNMS task is the ability to discriminate the test odors and then make a match/nonmatch comparison with the sample odor held in memory. Individual cells were found to discriminate various combinations of $\mathrm{M} / \mathrm{N}$, odor, and position in the test phase. Some exhibited activity, which was that of a "pure" place cell, discriminating the left/right position but not odor or match/nonmatch (Fig. 5C; $\chi_{(14)}^{2}=157.60, p<0.01$; position, $\left.F_{(1,267)}=57.81, p<0.01\right)$; odor, $F_{(1,267)}=2.02, \mathrm{NS} ; \mathrm{M} / \mathrm{N}, F_{(1,267)}$ $=1.93, \mathrm{NS})$. Other cells demonstrated conjunctive correlates such as position and $\mathrm{M} / \mathrm{N}$ (Fig. $5 D ; \chi^{2}{ }_{(24)}=201.94, p<0.01$; position, $F_{(1,249)}=45.03, p<0.01$; odor, $F_{(1,249)}=1.16$, NS; M/N, $F_{(1,247)}$ $=17.17, p<0.01)$, or position, odor, and M/N (Fig. $5 E ; \chi_{(21)}^{2}=$ 478.11, $p<0.01$; position, $F_{(1,485)}=29.61, p<0.01$; odor, $F_{(1,485)}$ $\left.=31.90, p<0.01 ; \mathrm{M} / \mathrm{N}, F_{(1,485)}=31.28, p<0.01\right)$.

Match/nonmatch activity most temporally coupled to reinforcement stimulus in $D G$, least in $C A 1$

To determine whether match/nonmatch discriminative firing around the test nosepoke response was associated with the behavioral execution of the nosepoke or was caused by differential responding to the water reward and light flash reinforcement, the reinforcement signal was delayed $1.5 \mathrm{sec}$ on a random number of trials. This was done for 16 of the 18 rats recorded. Postresponse match/nonmatch cells with a sufficient number $(>10)$ of reinforcement-delayed trials were classified as either reinforcement-correlated or poke-correlated, based on whether their poke-aligned or reinforcement-aligned perievent histogram contained the larger peak firing rate. An example of a match/nonmatch, reinforcement-correlated cell is shown in Figure $7 A$. The 


\section{Examples of Sample Odor Encoding}

\section{odor selectivity}

A
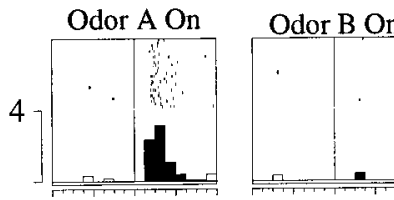

$\begin{array}{llllllllll}-2 & -1 & 0 & 1 & 2 & -2 & -1 & 0 & 1 & 2\end{array}$

Time (sec)

conjunctive odor, $\mathrm{C} / \mathrm{E}$ discrimination

B

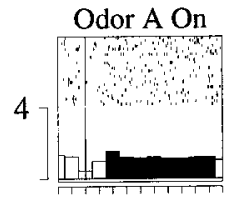

Odor B On

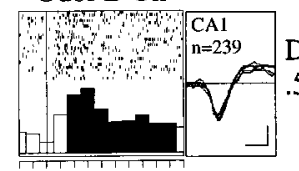

$-20$

$10-20$

10

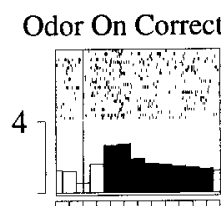

$-20$

$10-20$

Time (sec)

Examples of Test-Phase Encoding

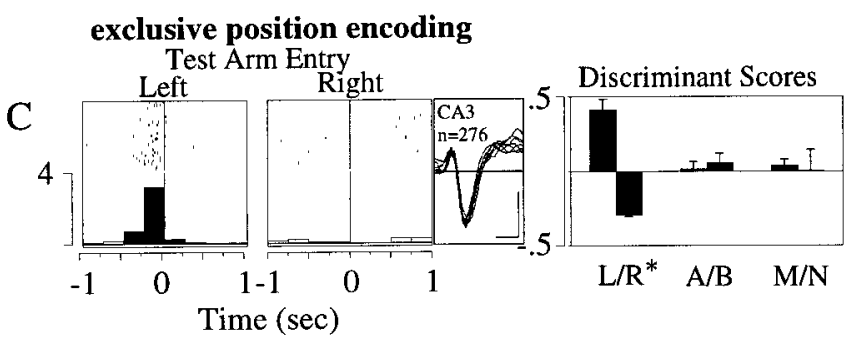

conjunctive position, $M / N$ encoding

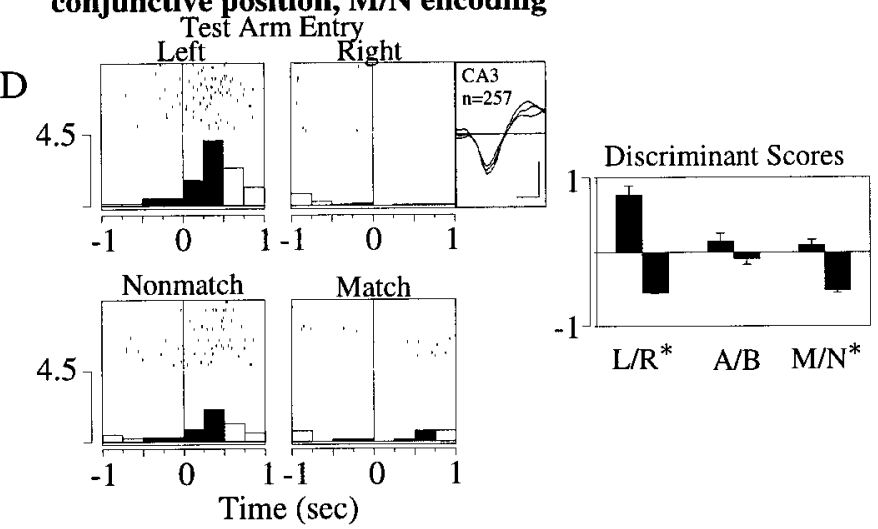

conjunctive position,odor, $M / N$ encoding

Test Nosepoke
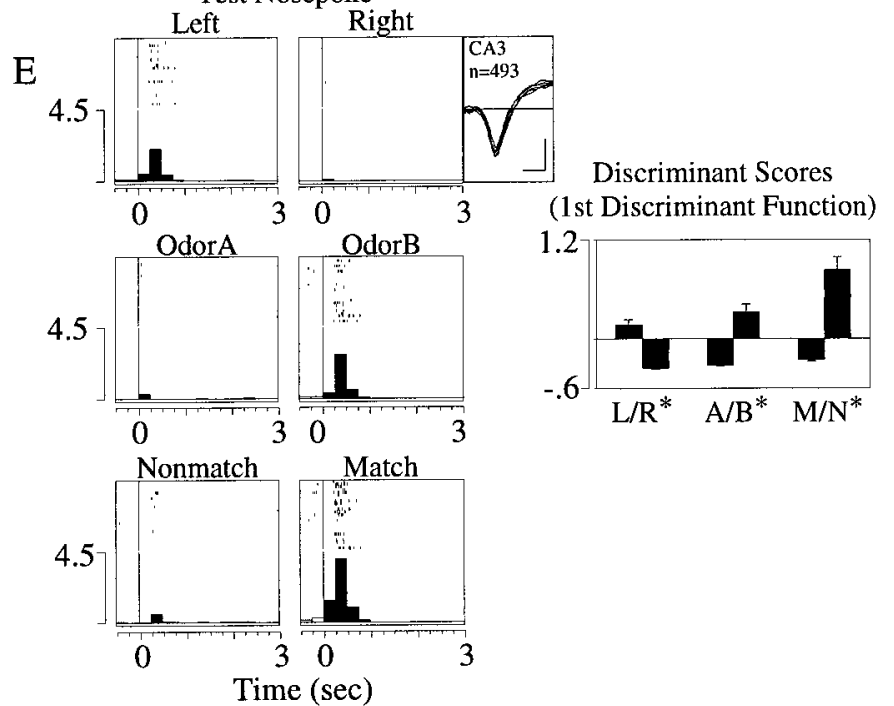

Figure 5. Examples of odor, position, and match/nonmatch discriminative firing. Panels show a raster display of 25 representative trials and a summary histogram of all trials recorded for each cell. Waveform (negative deflection-down; calibration: $100 \mu \mathrm{V}, 200 \mu \mathrm{sec}$ ), hippocampal field, number of trials recorded $(n)$, and significant $\left(\chi^{2} ; p<0.01\right)$ discriminant function scores (mean $\left.\pm \mathrm{SEM}\right)$ for odor $\mathrm{A} / \mathrm{B}(A / B)$, match/nonmatch $(M / N)$, or left $/ \mathrm{right}$ arm position $(L / R)$ are shown to the right of each panel. *Significant $(p<0.01)$ main effect of discriminant scores on the post hoc two-way or three-way ANOVAs. Sample phase: $A$, A cell discriminating odor but not correct versus error trials. $B$, A cell that discriminates both odor and correct/error trials in the slow sample-odor on period. Test phase: $C$, A cell with exclusive position $(L / R)$ encoding around test arm entry. $D$, A cell discriminating both $\mathrm{M} / \mathrm{N}$ trial type and position $(L / R)$ around test arm entry. $E$, Cell firing discriminating position, odor, and match/nonmatch in the postresponse period. More than one significant discriminant function existed for the perievent histogram of this cell. Only the first is shown, because it alone discriminated all three factors.

selective activity of the cell after match, but not nonmatch, responses $\left(\chi_{(84)}^{2}=372.75 ; p<0.01 ; \mathrm{M} / \mathrm{N}, F_{(1,257)}=172.97, p<\right.$ $0.01)$ was temporally correlated with the flash reinforcement signal, and hence greater in the reinforcement-centered versus the poke-centered perievent histogram. An example of a pokecorrelated cell is shown in Figure $7 B$. The increased activity after nonmatch responses compared to match responses $\left(\chi_{(84)}^{2}=\right.$ 275.16, $\left.p<0.01 ; \mathrm{M} / \mathrm{N}, F_{(1,119)}=10.27, p<0.01\right)$ was better temporally correlated with the nosepoke than to the water reinforcement, and hence larger in the poke-centered versus the reinforcement-centered perievent histogram. The difference between the maximal reinforcement-aligned and poke-aligned firing rates for the two cells is given in Figure $7 C$. This analysis was performed on 16 match/nonmatch cells in the dentate gyrus, 67 in CA3, and 19 in CA1. The percentage of match/nonmatch cells that were poke-correlated on both match and nonmatch trials was smallest in the dentate gyrus $(4 / 16=25 \%)$, more in CA3 $(25 / 67=$ $37 \%)$, and largest in CA1 $(9 / 19=47 \%)$ (Fig. $7 D)$.

Spatial representations dominate test-phase hippocampal encoding

Odor, match/nonmatch (including 66 cells in the test entry period, 41 cells in the prepoke period, and 38 poke-correlated cells from the postpoke period), and position cells (i.e., cells with main effects on post hoc ANOVAs) were tallied over all test-phase events, as shown in Table 2 and Figure $6 A$. Spatial encoding was observed in all three hippocampal fields $(\sim 70 \%$ of responsive cells in each subfield; 400/571 over all subfields) and was more than twice as prevalent as odor $(155 / 571=27 \%)$ and match/ nonmatch $(121 / 571=21 \%)$ encoding. Approximately one-third 
Table 3. Number of cells encoding sample-phase events

\begin{tabular}{|c|c|c|c|c|c|c|c|c|c|}
\hline & \multicolumn{3}{|c|}{ Odor on fast } & \multicolumn{3}{|c|}{ Odor on slow } & \multicolumn{3}{|c|}{ Odor off } \\
\hline & DG & CA3 & CA1 & DG & CA3 & CA1 & DG & CA3 & CA1 \\
\hline Responsive cells & 56 & 290 & 91 & 70 & 329 & 104 & 67 & 283 & 74 \\
\hline (\% total cells) & 43 & 38 & 44 & 54 & 43 & 51 & 52 & 37 & 36 \\
\hline Odor-selective cells & 5 & 27 & 11 & $0^{*}$ & 36 & 13 & 2 & 14 & 5 \\
\hline (\% responsive cells) & 9 & 9 & 12 & $0^{*}$ & 11 & 13 & 3 & 5 & 7 \\
\hline
\end{tabular}

$n$ (total): DG $=129 ;$ CA3 $=767 ;$ CA1 $=205$.

* Note: No DG cells discriminated odor in the odor on slow period.

(149/400) of the spatial cells encoded position exclusively, with no significant (ANOVA, $p<0.01$ ) main or interaction effects with regard to odor and match/nonmatch, whereas almost all of $\mathrm{M} / \mathrm{N}$ $(112 / 121)$ and odor cells (143/155) had spatial correlates (Table 2, Fig. 6A).

\section{Increased hippocampal activity for test stimuli which nonmatch the sample stimulus}

To investigate whether a recognition signal was present in the hippocampus on correctly performed trials and absent on error trials, the magnitude of perievent activity in nonmatch versus match trials was compared for all $\mathrm{M} / \mathrm{N}$-discriminating cells (including only poke-correlated cells from the postnosepoke period). The ratio of the mean perievent activity (averaging across all perievent time bins) for nonmatch $(\mathrm{N})$ versus match $(\mathrm{M})$ trials, $[(N-M) /(N+M)]$, is shown for the population of $M / N$ cells in Figure 8 . The majority of $\mathrm{M} / \mathrm{N}$-encoding cells $(84 / 121=70 \%)$ fired more robustly in the test phase on correct nonmatch trials than on error match trials (e.g., see cell shown in Fig. 5E), implying the existence of a behaviorally relevant hippocampal recognition memory signal.

Inverted distribution of odor specificity in test phase compared to sample phase; odor specificity of match/nonmatch comparison signals greatest in $D G$, least in $C A 1$

Odor representations in the test phase were distributed across the hippocampal fields in a graded fashion, inverse and statistically distinct $\left(\chi^{2}\right.$ test; $\left.\chi^{2}{ }_{(2)}=6.0 ; p<0.05\right)$ from that in the sample phase. DG cells demonstrated the greatest odor selectivity (24/ $75=32 \%)$, followed by CA3 $(103 / 383=27 \%)$, and CA1 $(28 /$ $113=24 \%)($ Fig. $6 D)$. The odor specificity of the match/nonmatch comparison cells (i.e., $\mathrm{M} / \mathrm{N}$ cells with conjunctive odor encoding) also varied inversely across the hippocampal fields compared to that of the responsive cells in the sample phase: largest in DG $(10 / 17=59 \%)$, followed by CA3 $(32 / 76=42 \%)$, and least in CA1 $(10 / 28=36 \%)$ (Fig. $6 C)$. The distribution of odor specificity in $\mathrm{M} / \mathrm{N}$ cells was distinct from that of the responsive cells in the sample phase $\left(\chi^{2}\right.$ test; $\left.\chi_{(2)}^{2}=9.4 ; p<0.01\right)$.

\section{DISCUSSION}

The DNMS experimental design of the present study, in contrast to those used by others (Otto and Eichenbaum, 1992b; Sakurai, 1994; Wood et al., 1999), allowed for separate analysis of sample versus recognition phase hippocampal encoding. The main findings were: (1) inverted sample- versus recognition-phase distributions of odor selectivity across hippocampal subfields; (2) more robust discriminative match/nonmatch signaling on correct versus error trials; and (3) conjunctive spatial with odor and $\mathrm{M} / \mathrm{N}$ encoding. A discussion of their relevance in terms of hippocampal processing during recognition memory follows.

\section{Hippocampal encoding of sample, delay, and test-phase events}

Neuronal activity in the three hippocampal subfields reflected all identifiable DNMS events. This agrees with previous findings from the CA3 and CA1 fields (Otto and Eichenbaum, 1992b; Hampson et al., 1993), but now extends them into dentate granule cells. The observation of slightly greater hippocampal responsivity to the sample ( $\sim 70 \%$ in each field) compared to the test odors $(\sim 55 \%)$ may be a consequence of the data analysis, which considered both increases and suppression of activity in the sample phase but only increases in the test phase. This was required because of the nonstationary nature of the test-phase events and

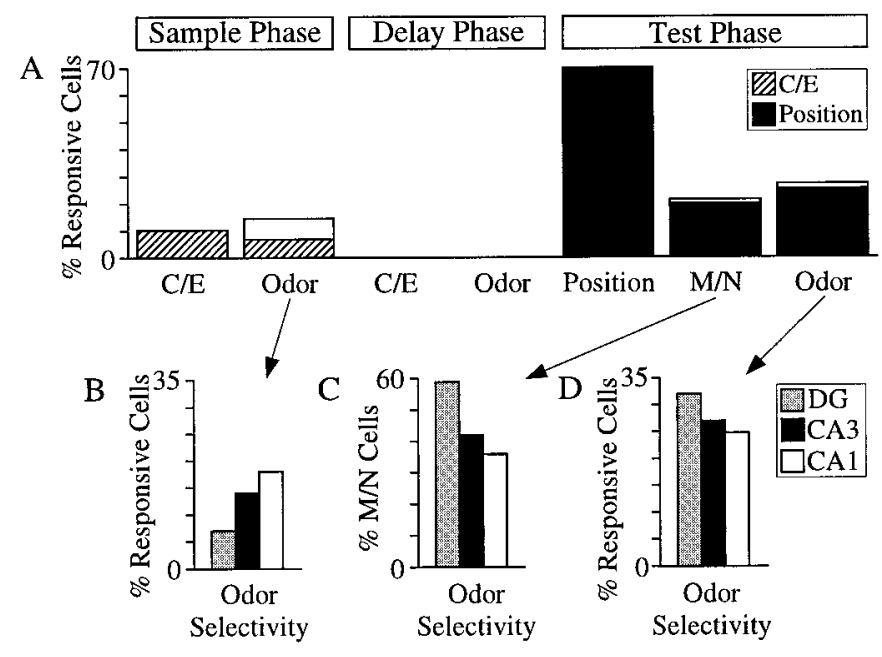

Figure 6. Summary of odor, match/nonmatch (correct/error), and position encoding in the DNMS task. $A$, Encoding properties of eventresponsive cells. Ten percent of the responsive cells in the sample phase exhibited differential activity in correct versus error trials. Sample odorselective activity was observed in $14 \%$ of the cells, half of which also fired differentially on correct versus error trials (hatched bars). No cells discriminated odor or correct/error trials in the delay period. In the test phase, spatial encoding was more than twice as predominant $(70 \%)$ as odor $(27 \%)$ and $\mathrm{M} / \mathrm{N}(21 \%)$. Almost all of the odor and match/nonmatch cells also discriminated position ( filled bars). B, Cells with odor selectivity in the sample phase were distributed across the hippocampal fields in a graded fashion, with CA1 cells demonstrating the greatest odor selectivity (18\%), then CA3 (14\%), and DG the least (7\%). In the test phase, the inverse distribution of odor selectivity was observed. $C$, Match/ nonmatch discriminating cells were most odor-selective in DG (59\%), followed by CA $3(42 \%)$, and least in CA1 $(36 \%)$. The distribution of odor selectivity of match/nonmatch cells was inverse and statistically distinct $\left(\chi_{(2)}^{2}=9.4 ; p<0.01\right)$ from the distribution of odor selectivity in the sample phase (shown in $B$ ). $D$, Odor encoding in the test phase was highest in DG (32\%), followed by CA3 $(27 \%)$, and least in CA1 $(24 \%)$. The inverted distribution of test-phase odor selectivity was statistically different $\left(\chi_{(2)}^{2}=6.0 ; p<0.05\right)$ from that in the sample phase in $B$. 
reinforcement-correlated $M / N$ encoding

A

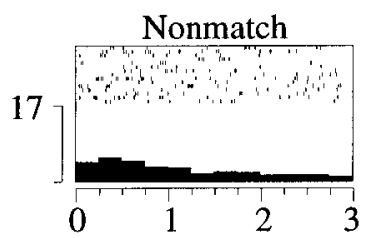

Match

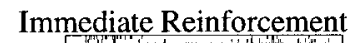

Post-Nosepoke

Match
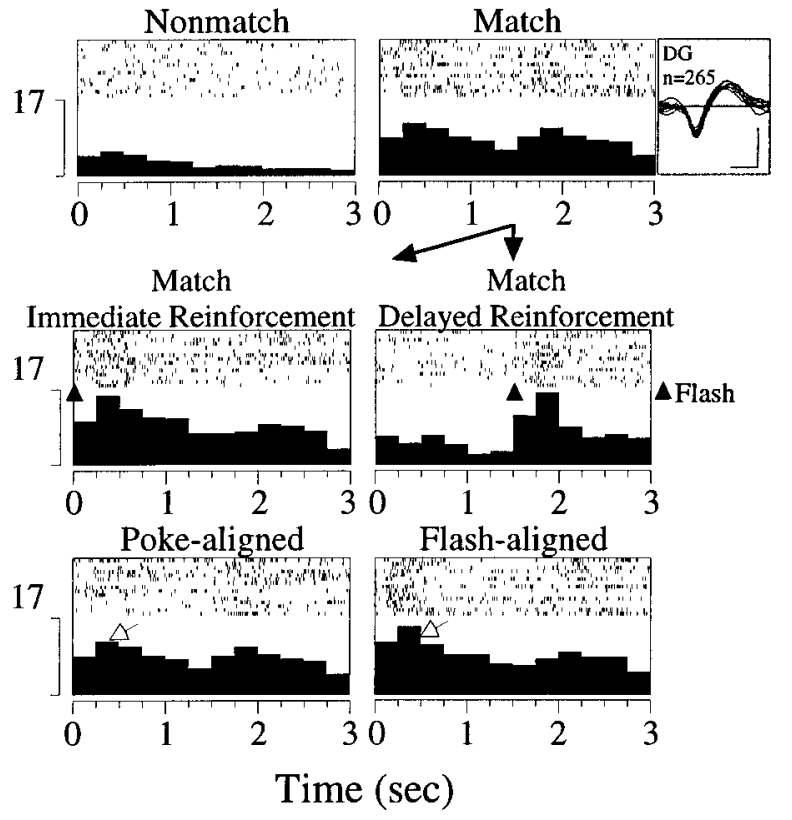

B

\section{poke-correlated $\mathrm{M} / \mathrm{N}$ encoding}

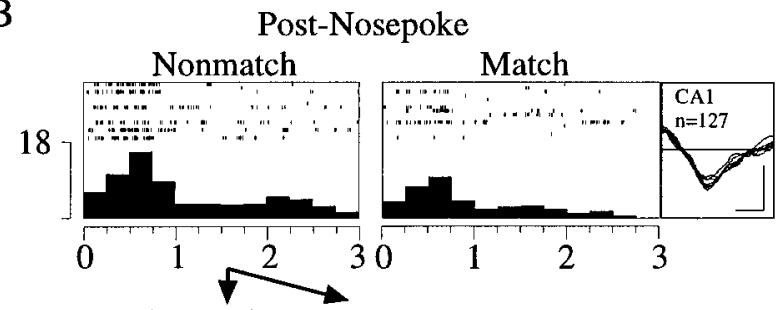

Nonmatch

Immediate Reinforcement Delayed Reinforcement

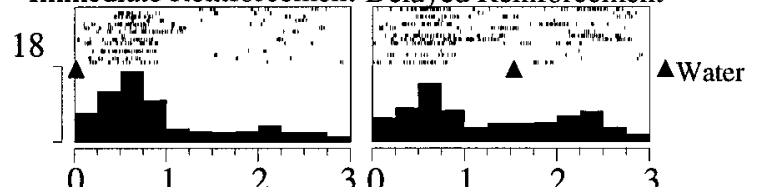

Poke-aligned

18

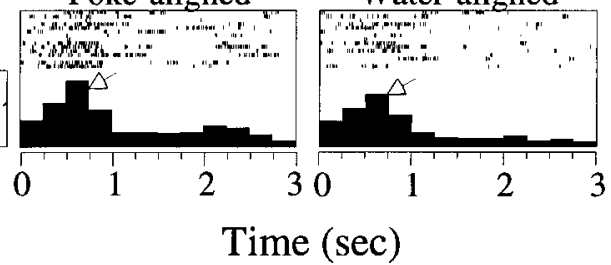

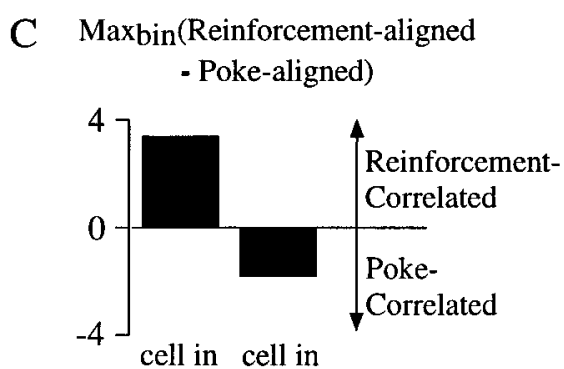

(A) (B)
D

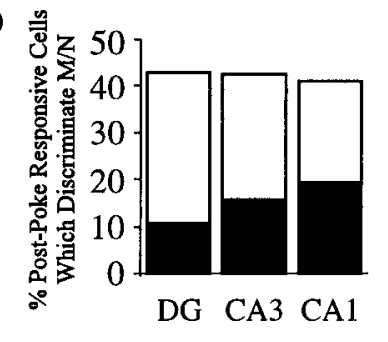

Reinforcement-correlated

Poke-correlated

Figure 7. Determination of poke- versus reinforcement-correlated match/nonmatch discriminative firing. Panels show a perievent histogram of all trials recorded for each cell and a raster display of 15 representative trials. Waveform (negative deflection-down; calibration: $100 \mu \mathrm{V}, 200 \mu$ sec), hippocampal field, and number of trials recorded $(n)$ are shown to the right. A, Top panels, Cell with elevated activity after match poke responses (right) but not nonmatch poke responses (left). Middle panels, Postpoke match activity on trials when the reinforcement signal (light flash) was delivered immediately $(l e f t)$ or was delayed by $1.5 \mathrm{sec}($ right $)$. Note the shifting of activity with the reinforcement signal. Bottom panels, Perievent histogram of activity around the match poke response (left) and the flash reinforcement signal (right). The activity is better time-locked (i.e., larger maximal firing rate) to the flash reinforcement than to the poke response (plotted in $C$ ). B, Top panels, Cell with more robust activity after nonmatch poke responses in the test arms (left) than after match poke responses (right). Middle panels, Postpoke nonmatch activity on trials when the reinforcement signal (water reward) was delivered immediately (left) or was delayed by $1.5 \mathrm{sec}($ right $)$. The majority of activity did not shift with the reinforcement signal. Bottom panels, Perievent histogram of activity around the nonmatch poke response (left) and the water reinforcement signal (right). The activity was better time-locked (i.e., larger maximal firing rate) to the poke response than to the water reinforcement (plotted in $C$ ). $C$, Comparison of peak firing rate in perievent histogram centered around the reinforcement signal relative to that centered around the poke response for cells shown in $A$ and $B$. The cell shown in $A$, with greater maximal firing in the reinforcement-centered perievent histogram relative to the poke-centered perievent histogram, had reinforcement-correlated $\mathrm{M} / \mathrm{N}$ firing. The cell shown in $B$, with the converse, had poke-correlated $\mathrm{M} / \mathrm{N}$ firing. $D$, Summary of match/nonmatch discrimination in postpoke period. The total percentage of cells that differentiated match versus nonmatch trials was $\sim 43 \%$ in each subfield. Of these cells, however, DG had the smallest percentage of poke-correlated cells (25\%), followed by CA3 (37\%), and CA1 with the greatest (47\%), as determined using the criteria outlined in $A-C$.

the necessity to avoid confounding event-related decreases in activity with low, out-of-field place cell firing. The restriction to increases in activity was not required for sample-phase events that occurred at a common location.

Although a significant number of cells in each subfield $(\sim 25 \%)$ exhibited delay firing, the activity did not represent a memory of the sample odor or predict performance on the task (Table 2), in agreement with other reports (Cahusac et al., 1989; Colombo and Gross, 1994). It should be noted, however, that only two odors were used in the task and cells classified as nonsample odorselective may have been more broadly tuned or selective for odors (or features of stimuli in other modalities) not manipulated in the study. Nevertheless, the data obtained with the DNMS task used here suggests that the hippocampus converts afferent cue-specific cortical activity during the delay, which represents "what" is being remembered (Miyashita and Chang, 1988; Young et al., 1997), into a more generalized, cue-nonspecific representation signaling simply "that" information is being held in memory. In contrast to the complete removal of cue-specific information from afferent cortical signals in the delay phase, cue-specificity filtering in the hippocampus occurred in a flexible and more complex form in the sample and test phases, as discussed below. 


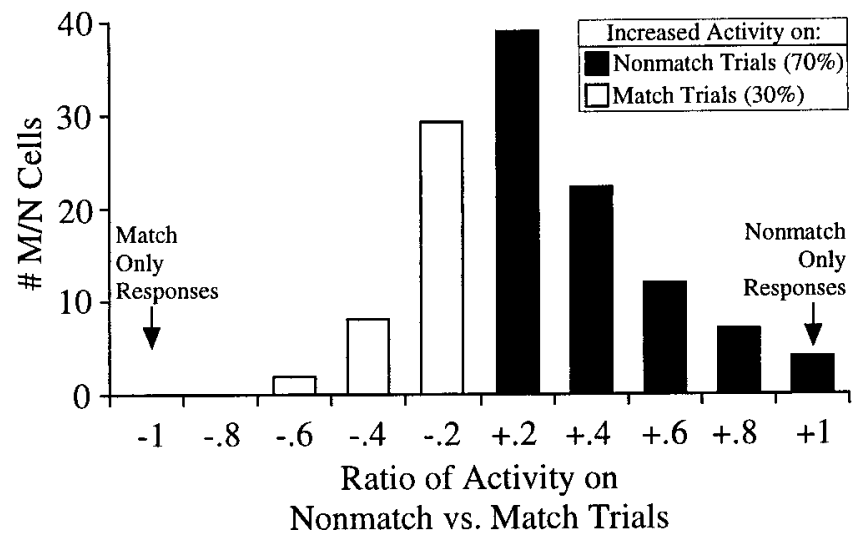

Figure 8. Increased hippocampal activity on correct nonmatch trials. Ratio of mean activity of match/nonmatch discriminating cells on nonmatch versus match trials $((\mathrm{N}-\mathrm{M}) /(\mathrm{N}+\mathrm{M}))$. The majority $(70 \%)$ of match/nonmatch comparison cells in the test phase exhibited greater activity on correct nonmatch trials than on error match trials. Note: On the $x$-axis, +.2 implies $0-20 \%$ increase in activity on nonmatch versus match trials, +.4 implies $20-40 \%$ increase, -.2 implies $0-20 \%$ decrease, etc.

\section{Sample cue-selective activity most prominent in CA1, least in DG, and linked to task performance}

Some studies have suggested that the encoding of specific perceptual variables within the DNMS task (e.g., odor identity within an odor-guided task) is reserved to the parahippocampal cortical regions and does not occur in the hippocampus (Brown et al., 1987; Riches et al., 1991; Otto and Eichenbaum, 1992b; Young et al., 1997). Others have shown that the hippocampus does represent perceptual variables (Wood et al., 1999) and, moreover, that DNMS performance is contingent on their correct hippocampal encoding in the sample phase (Deadwyler et al., 1996; Hampson et al., 1999). The data presented here are in accord with the latter. Cells in CA1, and to a lesser degree CA3, preferentially encoded sample odor identity. This indicates that perceptual information about the sample item does reach the CA fields, perhaps via the direct perforant path projection (Witter, 1993). Moreover, the restriction of odor encoding to the CA fields in the slow-odor onset period indicates that sustained, reverberant sample-item processing occurs exclusively in pyramidal and not dentate granule cells. This shunting of sensory processing away from the dentate gyrus and into pyramidal cell layers may explain the increased c-fos mRNA expression in CA1 relative to dentate/CA3 regions seen after exploration of novel olfactory environments (Hess et al., 1995). The fact that activity in half of the sampleselective cells also predicted performance in the test phase (different coding on correct vs error trials) suggests that the hippocampal representation of the sample odor may be important for mediating its memory across the delay.

\section{Integration of spatial representations with odor and $M / N$ recognition encoding}

There has been debate as to whether the hippocampus is primarily dedicated to spatial processing (O'Keefe and Nadel, 1978) or whether it is capable of mediating general memory functions independent of spatial factors (Squire, 1992; Eichenbaum et al., 1994; Vargha-Khadem et al., 1997). Eichenbaum and colleagues have argued for the general memory function role, with a significant proportion (up to 50\%) of hippocampal neurons encoding perceptual/cognitive variables independent of spatial location (Wood et al., 1999). The results presented here argue against location-independent perceptual and mnemonic processing in the hippocampus. The majority of odor and match/nonmatch cells had spatial correlates. In contrast, approximately one-third of all position cells exclusively encoded space. Moreover, spatial encoding was twice as prevalent with respect to cell numbers as odor and match/nonmatch. This discrepancy with the findings of Wood et al. (1999) may be caused in part by the low odordimensionality of our task and the fact that DNMS performance occurred in an enclosed Y-shaped apparatus with only proximal, intramaze visual cues. The lack of distal, extramaze cues and the rat's inability to view its environment through multiple perspectives may have resulted in less flexible spatial representations and greater fusion of spatial with olfactory and recognition memory codes. Additional experiments will be required to evaluate this possibility.

Notwithstanding, our data suggest that spatial codes are integrated into nonspatial representations, with hippocampal activity encoding stimulus properties and $\mathrm{M} / \mathrm{N}$ comparisons when they occur at a particular location. The delay activity also appeared to be tied in with spatial representations, always restricted to the sample arm location and extinguishing when the rat moved toward the test arms. It is uncertain, however, whether the location dependence of the delay activity was attributable to the integration of spatial representations with the mnemonic delay signaling or whether cessation of activity was caused by the impingement of intervening visual stimuli as the rat turned to leave the sample arm. The presence of interposing stimuli may be sufficient to disrupt the bridging activity between the sample and test cues, as has been observed in the monkey perirhinal cortex (Miller et al., 1993).

\section{Test cue-specificity distribution (DG > CA3 > CA1) inverse of that for the sample cue}

Differential encoding of stimuli presented in the sample versus test phase of recognition memory tasks has been observed in the hippocampal formation of monkeys (Riches et al., 1991), rats (Deadwyler et al., 1996), and humans (Lepage et al., 1998; Schacter and Wagner, 1999). Our results confirm and extend these observations by showing an inversion of the distribution of cue (odor)-selective activity in the sample (CA1 > CA3 > DG) versus the test $(\mathrm{DG}>\mathrm{CA} 3>\mathrm{CA} 1)$ phase of the DNMS task. The inverted test cue-specificity gradient was even more pronounced in cells representing the match/nonmatch comparisons central to DNMS performance.

\section{Evidence for generalization of behaviorally used recognition memory codes in the hippocampus}

Differential unit responses to test stimuli that match versus nonmatch the sample have been reported in both the hippocampus (Otto and Eichenbaum, 1992b; Rolls et al., 1993) and parahippocampal regions (Miller and Desimone, 1994; Suzuki et al., 1997; Young et al., 1997). The match/nonmatch signals have been interpreted as the neural substrate for recognition memory, contributing to the animal's decision about whether stimuli have been encountered in the recent past. Most of these studies however, because of the use of the continuous DNMS paradigm with short delays, had few error trials and subsequently were unable to evaluate the behavioral relevance of these recognition signals. The more robust activity on nonmatch versus match trials observed here provides evidence for the presence of a match/ nonmatch comparison signal in the hippocampus on correct trials, where recognition occurred, and its absence on error trials where recognition failed. 

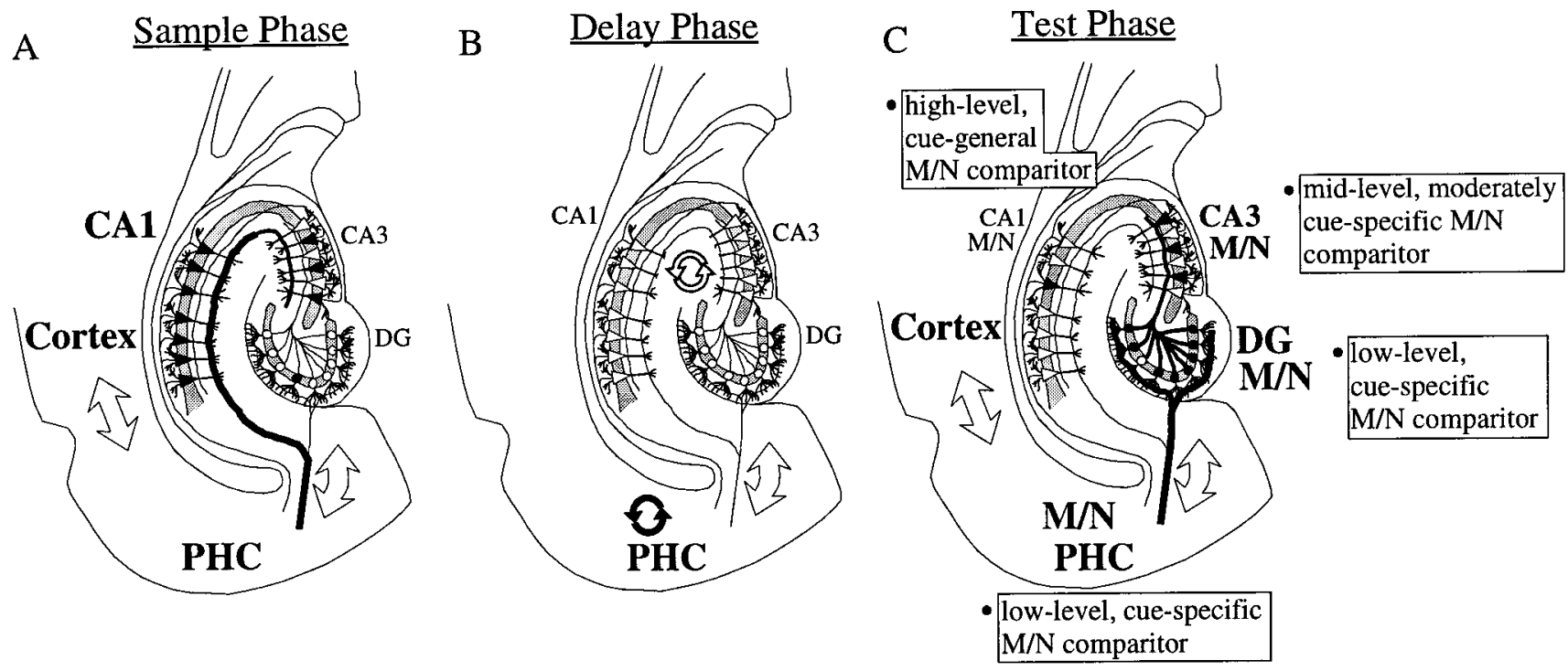

Figure 9. Schematic diagram of odor encoding in the temporal lobe during olfactory recognition memory performance. Odor selectivity is denoted by large bold text, thick lines, and filled symbols. A, Sample phase. Odor cue-specific activity occurs in the neocortical structures, parahippocampal cortex (PHC), and CA1 (perhaps because of the direct, perforant path projection from the entorhinal cortex to CA1). B, Delay phase. PHC maintains sustained, cue-specific activation traces ( filled, curved arrows). Hippocampal fields maintain sustained, cue-nonspecific activation traces (open, curved arrows). $C$, Test recognition phase. Match/nonmatch $(M / N)$ comparisons between the sample (held in memory) and test cues occur in the PHC and in each hippocampal subfield, but with a graded odor cue-specificity: Cortex/PHC $>$ DG $>$ CA3 $>$ CA1. Odor representations enter the hippocampus via the perforant path projection from entorhinal cortex to DG, and the mossy fiber DG $\rightarrow$ CA3 projection. The $\mathrm{M} / \mathrm{N}$ comparison signal is present in the hippocampus on correct trials, when accurate memory of the sample item is demonstrated, and absent on error trials, when memory for the sample fails. The hippocampal circuit, therefore, transforms the cue-specific cortical signals into abstracted, cue-general recognition memory representations for use in guiding behavior.

The finding of progressively diminished odor specificity of match/nonmatch cells along the DG $\rightarrow$ CA3 $\rightarrow$ CA1 circuit provides the first evidence for an intrahippocampal processing role in the transformation of the cue-specific match/nonmatch signals observed in parahippocampal cortices (Brown et al., 1987; Miller et al., 1993; Young et al., 1997) into the abstracted, cuegeneral match/nonmatch comparison cells of CA1 (Sakurai, 1990; Otto and Eichenbaum, 1992b). The generalization of recognition memory representations appears to be unique to the hippocampus and an intrinsic function of hippocampal circuitry during recall, constituting an important extension to stimulus-specific cortical memory processing (Eichenbaum et al., 1996). Moreover, odor-selective activity in the hippocampus was restricted to different subfields depending on the phase of the DNMS task: CA1, and to a lesser extent CA3, in the sample phase; no subfields in the delay phase; and DG, and to a lesser extent CA3, in the test phase (illustrated schematically in Fig. 9). This reveals the hippocampus to be a highly dynamic and flexible encoding device, capable of processing sensory information within different regions depending on task contingencies.

\section{REFERENCES}

Alvarez P, Zola-Morgan S, Squire LR (1995) Damage limited to the hippocampal region produces long-lasting impairment in monkeys. J Neurosci 15:3796-3807.

Brown MW, Wilson FA, Riches IP (1987) Neuronal evidence that infero-medial temporal cortex is more important than hippocampus in certain processes underlying recognition memory. Brain Res 409:158-162.

Cahusac PMB, Miyashita Y, Rolls ET (1989) Responses of hippocampal formation neurons in the monkey related to delayed spatial response and object-place memory tasks. Behav Brain Res 33:229-240.
Colombo M, Gross CG (1994) Responses of inferior temporal cortex and hippocampal neurons during delayed matching to sample in monkeys (Macaca fascicularis). Behav Neurosci 108:443-455.

Deadwyler SA, Bunn T, Hampson RE (1996) Hippocampal ensemble activity during spatial delayed-nonmatch-to-sample performance in rats. J Neurosci 16:354-372.

Eichenbaum H, Otto T, Cohen NJ (1994) Two functional components of the hippocampal memory system. Behav Brain Sci 17:449-517.

Eichenbaum H, Schoenbaum G, Young B, Bunsey M (1996) Functional organization of the hippocampal memory system. Proc Natl Acad Sci USA 93:13500-13507.

Hampson RE, Heyser CJ, Deadwyler SA (1993) Hippocampal cell firing correlates of delayed-match-to-sample performance in the rat. Behav Neurosci 107:715-739.

Hampson RE, Jarrard LE, Deadwyler SA (1999) Effects of ibotenate hippocampal and extrahippocampal destruction on delayed-match and -nonmatch-to-sample behavior in rats. J Neurosci 19:1492-1507.

Hess US, Lynch G, Gall CM (1995) Regional patterns of c-fos mRNA expression in rat hippocampus following exploration of a novel environment versus performance of a well-learned discrimination. J Neurosci 15:7796-7809.

Jarrard LE (1993) On the role of the hippocampus in learning and memory in the rat. Behav Neural Biol 60:9-26.

Jung MW, McNaughton BL (1993) Spatial selectivity of unit activity in the hippocampal granular layer. Hippocampus 3:165-182.

Lepage M, Habib R, Tulving E (1998) Hippocampal PET activations of memory encoding and retrieval: the HIPER model. Hippocampus $8: 313-322$.

McNaughton BL, O'Keefe J, Barnes CA (1983) The stereotrode: a new technique for simultaneous isolation of several single units in the central nervous system from multiple unit records. J Neurosci Methods 8:391-397.

Meunier M, Bachevalier J, Mishkin M, Murray EA (1993) Effects on visual recognition of combined and separate ablations of the entorhinal and perirhinal cortex in rhesus monkeys. J Neurosci 13:5418-5432.

Miller EK, Desimone R (1994) Parallel neuronal mechanisms for shortterm memory. Science 263:520-522. 
Miller EK, Li L, Desimone R (1991) A neural mechanism for working and recognition memory in inferior temporal cortex. Science 254:1377-1379.

Miller EK, Li L, Desimone R (1993) Activity of neurons in anterior inferior temporal cortex during a short-term memory task. J Neurosci 13:1460-1478.

Miyashita Y, Chang HS (1988) Neuronal correlate of pictorial shortterm memory in the primate temporal cortex. Nature 331:68-70.

Mizumori SJY, McNaughton BL, Barnes CA (1989) A comparison of supramammillary and medial septal influences on hippocampal field potentials and single-unit activity. J Neurophysiol 61:15-31.

Mumby DG, Pinel JPJ (1994) Rhinal cortex lesions and object recognition in rats. Behav Neurosci 108:11-18.

O'Keefe J, Nadel L (1978) The hippocampus as a cognitive map. London: Oxford UP.

Otto T, Eichenbaum H (1992a) Complementary roles of the orbital prefrontal cortex and the perirhinal-entorhinal cortices in an odorguided delayed-nonmatching-to-sample task. Behav Neurosci 106:762-775.

Otto T, Eichenbaum H (1992b) Neuronal activity in the hippocampus during delayed non-match to sample performance in rats: evidence for hippocampal processing in recognition memory. Hippocampus 2:323-334.

Ranck JB (1973) Studies on single neurons in dorsal hippocampal formation and septum in unrestrained rats. Part I. Behavioral correlates and firing repertoires. Exp Neurol 41:461-555.

Rencher AC (1995) Methods of multivariate analysis. New York: Wiley. Riches IP, Wilson FAW, Brown MW (1991) The effects of visual stimulation and memory on neurons of the hippocampal formation and the neighboring parahippocampal gyrus and inferior temporal cortex of the primate. J Neurosci 11:1763-1779.
Rolls ET, Cahusac PM, Feigenbaum JD, Miyashita Y (1993) Responses of single neurons in the hippocampus of the macaque related to recognition memory. Exp Brain Res 93:299-306.

Sakurai Y (1990) Hippocampal cells have behavioral correlates during the performance of an auditory working memory task in the rat. Behav Neurosci 104:253-263.

Sakurai Y (1994) Involvement of auditory cortical and hippocampal neurons in auditory working memory and reference memory in the rat. J Neurosci 14:2606-2623.

Schacter DL, Wagner AD (1999) Medial temporal lobe activations in fMRI and PET studies of episodic encoding and retrieval. Hippocampus 9:7-24.

Schoenbaum G, Eichenbaum H (1995) Information coding in the rodent prefrontal cortex. I. Single-neuron activity in orbitofrontal cortex compared with that in piriform cortex. J Neurophysiol 74:733-750.

Squire LR (1992) Memory and the hippocampus: a synthesis from findings with rats, monkeys, and humans. Psychol Rev 99:195-231.

Suzuki WA, Miller EK, Desimone R (1997) Object and place memory in the macaque entorhinal cortex. J Neurophysiol 78:1062-1081.

Vargha-Khadem F, Gadian DG, Watkins KE, Connelly A, Paesschen WV, Mishkin M (1997) Differential effects of early hippocampal pathology on episodic and semantic memory. Science 277:376-380.

Witter MP (1993) Organization of the entorhinal-hippocampal system: a review of current anatomical data. Hippocampus 3:33-44.

Wood ER, Mumby DG, Pinel JP, Phillips AG (1993) Impaired object recognition memory in rats following ischemia-induced damage to the hippocampus. Behav Neurosci 107:51-62.

Wood ER, Dudchenko PA, Eichenbaum H (1999) The global record of memory in hippocampal neuronal activity. Nature 397:613-616.

Young BJ, Otto T, Fox GD, Eichenbaum H (1997) Memory representation within the parahippocampal region. J Neurosci 17:5183-5195. 